\title{
Effect of nitrosamine safe diisopropyl xanthogen polysulfide accelerator on cure and static mechanical properties of natural rubber compounds
}

\author{
I H K Samarasinghe*, D G Edirisinghe*, S Walpalage** and S M Egodage** \\ * Rubber Research Institute of Sri Lanka, Telewala Road, Ratmalana, Sri Lanka \\ ** University of Moratuwa, Katubedda, Sri Lanka
}

\begin{abstract}
Sulfur vulcanization of natural rubber (NR) is mainly carried out with the use of accelerators in order to achieve desired network structure and consequently the specific material properties. Many traditional organic accelerators are made from secondary amines and are capable of nitrosation during and after vulcanization in the presence of nitrosating agents. Therefore, the use of most of the nitrosamine generating traditional accelerators in rubber formulations are restricted by stringent rules and regulations imposed by world environmental and health-related government agencies. Diisopropyl Xanthogen Polysulfide (DIXP) has been identified as a nitrosamine safe novel accelerator and literature on use of this accelerator in natural rubber compounds is limited. The aim of this study was to evaluate the influence of DIXP on cure and static mechanical properties of NR compounds. A series of NR compounds was prepared with DIXP by varying the accelerator dosage from $0.2 \mathrm{phr}$ to $2.2 \mathrm{phr}$ at $0.4 \mathrm{phr}$ intervals. Cure and static mechanical properties of the compounds were evaluated and compared with those of the compounds prepared with the commonly used nitrosamine safe N-tert-butyl-2-benzothiazole sulfenamide (TBBS) accelerator. Results showed that most of the properties of NR compounds prepared with DIXP are inferior in comparison to those of the compounds prepared with TBBS. Nevertheless, NR compounds prepared with DIXP possessed satisfactory results in regard to optimum cure time and elongation at break.
\end{abstract}

Key words: cure characteristics, mechanical properties, nitrosamine safe accelerators, natural rubber, sulphur vulcanization

\section{Introduction}

Human exposure to nitrosamines in the rubber industry has been a matter of concern in recent years with the presence of $\mathrm{N}$-nitrosamines in vulcanized rubber products (Blackley, 2012). N-nitroso compounds, which are known as genotoxic and carcinogenic
(Fishbein, 2011; Vieira et al., 2006; Iavicoli and Carelli, 2006) are formed by the reaction of a substance containing secondary amine groups and a nitrosating agent derived from the oxides of nitrogen (NOx) or nitrite as shown in the Fig. 1 (Goss et al., 2006). Four classes of common rubber 
Nitrosamine safe accelerators for dry rubber compounds

accelerators have been identified as generating secondary amine intermediates during vulcanization (Goss et al., 2006). They are dithiocarbamates, sulfenamides, sulfur donors and thiurams (Goss et al., 2006). Most of the accelerators used in the industry belong to the above classes and are used in amounts of up to $1 \%$ by weight of rubber. Hence, substantial amount of secondary amines are capable of nitrosation during and after the vulcanization (Stevenson, 1987).

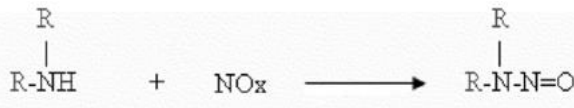

Fig. 1. Nitrosation of secondary amines

Therefore, use of such accelerators are restricted by stringent rules and regulations specially in food grade rubber products and products directly used by humans including gloves, balloons, toys, baby bottle teats, soothers and condoms. For instance, European legislation has limited the release of $\mathrm{N}$-nitrosamines and $\mathrm{N}$ nitrosatable compounds in teats and soothers to 0.01 and $0.1 \mathrm{mg} / \mathrm{kg}$ rubber respectively (Proksch, 2001).

Development of nitrosamine safe accelerators, which do not produce nitrosamines or which produce nonregulated nitrosamines is an alternative to reduce or eliminate the production of nitrosamines and recently research work on incorporation of such accelerators in rubber formulations has gained considerable scientific interest.
Sulfenamides are known as semi-ultra, delayed-action accelerators due to their fast cure rate and good processing safety. Three commercially available sulfenamide accelerators have been identified as accelerators which do not produce regulated nitrosamines (Goss $e t$ al., 2006). They are N-cyclohexyl-2benzothiazole sulfenamide (CBS), Ntert-butyl-2-benzothiazole sulfenamide (TBBS) and N,N'-dicyclohexyl-2benzothiazole sulfenamide (DCBS). The other three popular sulfenamides are based on morpholine and can generate the regulated nitrosomorpholine. They are 2-morpholino dithiobenzothiazole (MBSS), Noxydiethylene-2-benzothiazole sulfonamide (OBTS or MBS) and N-oxy diethylene thiocarbamyl-N-oxydiethyl sulfenamide (OTOS) (Goss et al., 2006).

Xanthogen accelerators contain oxygen in the accelerator backbone. Diisopropyl xanthogen polysulfide (DIXP) is a nitrogen free commercially available novel accelerator and thus it does not produce harmful $\mathrm{N}$-nitrosamines during curing (Ohbi et al., 2007). Further, DIXP is believed to be totally consumed during the vulcanization process without leaving any reaction byproduct (Ohbi et al., 2007). Although utilization of DIXP has been reported in natural rubber (NR) latex, its use for curing of dry NR is rare. The aim of this study was to determine the effect of nitrosamine safe DIXP accelerator on cure and static mechanical properties of dry NR based efficient sulfur vulcanized (EV) compounds. 
I H K Samarasinghe et al.

\section{Materials and Methods \\ Materials}

NR (crepe 1X) used in this study was obtained from the Payagala Estate crepe rubber manufacturing factory. The accelerator DIXP (Robac AS100) was supplied by Robinson Brothers Limited, Phoenix Street, West Bromwich, B70 OAH, UK. Accelerator TBBS as well as other commercial grade rubber chemicals namely $99.5 \%$ zinc oxide $(\mathrm{ZnO})$, stearic acid, styrenated phenolic type antioxidant (Lovinox WSP) and sulphur were purchased from Glorchem (Pvt.) Ltd., Sri Lanka.

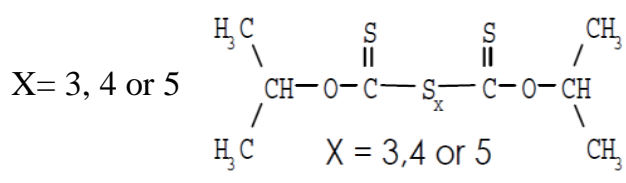

Fig. 2. Chemical structure of DIXP

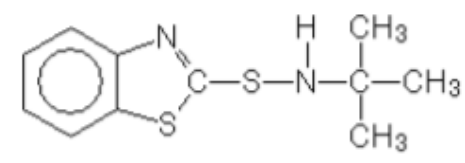

Fig. 3. Chemical structure of TBBS

\section{Compounding and testing methods}

Two series of NR compounds were prepared with DIXP (D series) and TBBS (T series- Control) by varying the accelerator loading from $0.2 \mathrm{phr}$ to 2.2 phr at 0.4 phr intervals. The formulation employed for the study is shown in Table 1. The compounding of NR was done on a two-roll open mill as per ASTM D 3184. The rheographs of the mixes and their cure characteristics were obtained using Rubber Process
Analyser (Model: TA Instruments RPA Flex). The test specimens were prepared by molding in an electrically heated hydraulic press at $150{ }^{\circ} \mathrm{C}$ for the optimum cure time. Tensile and tear strengths were measured according to ISO 37:2010 and ISO 34-1:2010, respectively using an Instron tensile testing machine, at a cross-head speed of $500 \mathrm{~mm} / \mathrm{min}$. Hardness of the cured compounds was measured according to ASTM-D-2240 using a Shore A type Durometer.

\section{Results and Discussion \\ Cure characteristics}

The rheographs of the mixes cured at $150{ }^{\circ} \mathrm{C}$ using DIXP and TBBS are given in Fig. 4 and 5, respectively. Influence of DIXP accelerator on cure characteristics of NR compounds were compared with those of the control compounds prepared with TBBS (Fig. 6 and Fig. 7).

Fig. 6 shows that the cure time $\left(t_{90}\right)$ of the compounds reduced with the increase of DIXP, while that of the compounds accelerated with TBBS is increased as the accelerator concentration is increased. This could be attributed to the ultra-fast activity of DIXP and semi-ultra-delayed-action activity of TBBS. TBBS accelerated systems provide two functions during vulcanization of rubber compounds. Initially, they retard the vulcanization that increases the scorch time and the rubber compounds can be safely processed. Secondly they react with zinc oxide to form a complex that accelerates polysulfidic crosslink formation (Coran, 2003; Ghosh et al., 
Nitrosamine safe accelerators for dry rubber compounds

2003). The higher cure times observed for vulcanizates prepared with TBBS in comparison to that of vulcanizates prepared with DIXP is probably a result of the above mentioned delayed action process.

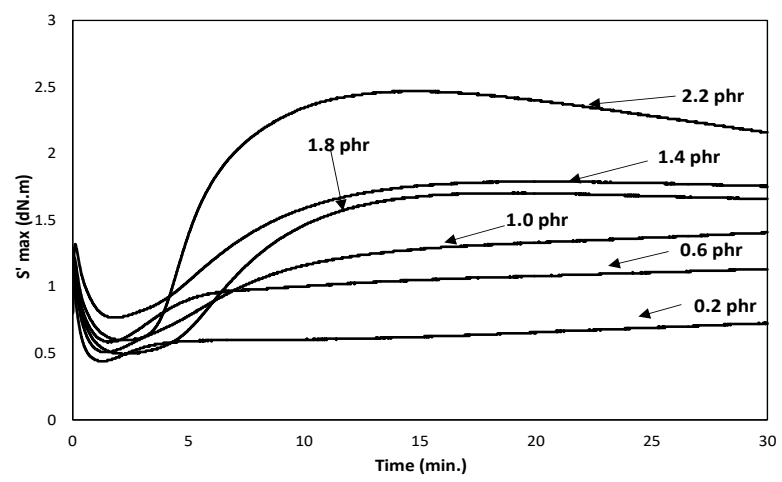

Fig. 4. Rheographs of NR compounds cured using different DIXP dosages

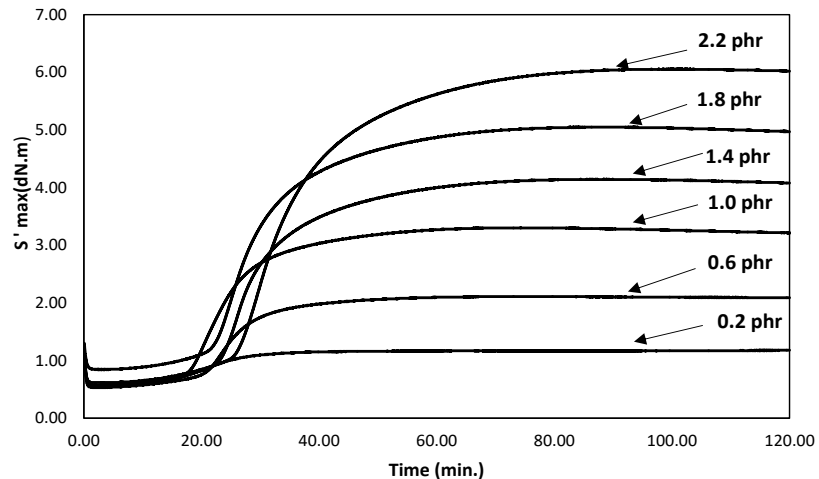

Fig. 5. Rheographs of NR compounds cured using different TBBS dosages

Table 1. Formulations of the two series ( $T$ and $D$ ) of NR compounds

\begin{tabular}{lrrrrrrrrrrrr}
\hline & \multicolumn{11}{c}{ Parts per hundred parts of rubber (phr) } \\
\cline { 2 - 13 } Ingredient & $\mathrm{T}$ & $\mathrm{T}$ & $\mathrm{T}$ & $\mathrm{T}$ & $\mathrm{T}$ & $\mathrm{T}$ & $\mathrm{D}$ & $\mathrm{D}$ & $\mathrm{D}$ & $\mathrm{D}$ & $\mathrm{D}$ & $\mathrm{D}$ \\
& 0.2 & 0.6 & 1.0 & 1.4 & 1.8 & 2.2 & 0.2 & 0.6 & 1.0 & 1.4 & 1.8 & 2.2 \\
\hline NR & 100 & 100 & 100 & 100 & 100 & 100 & 100 & 100 & 100 & 100 & 100 & 100 \\
ZnO & 5 & 5 & 5 & 5 & 5 & 5 & 5 & 5 & 5 & 5 & 5 & 5 \\
Stearic acid & 2 & 2 & 2 & 2 & 2 & 2 & 2 & 2 & 2 & 2 & 2 & 2 \\
WSP & 1 & 1 & 1 & 1 & 1 & 1 & 1 & 1 & 1 & 1 & 1 & 1 \\
TBBS & 0.2 & 0.6 & 1 & 1.4 & 1.8 & 2.2 & - & - & - & - & - & - \\
DIXP & - & - & - & - & - & - & 0.2 & 0.6 & 1 & 1.4 & 1.8 & 2.2 \\
Sulphur & 0.5 & 0.5 & 0.5 & 0.5 & 0.5 & 0.5 & 0.5 & 0.5 & 0.5 & 0.5 & 0.5 & 0.5 \\
\hline
\end{tabular}




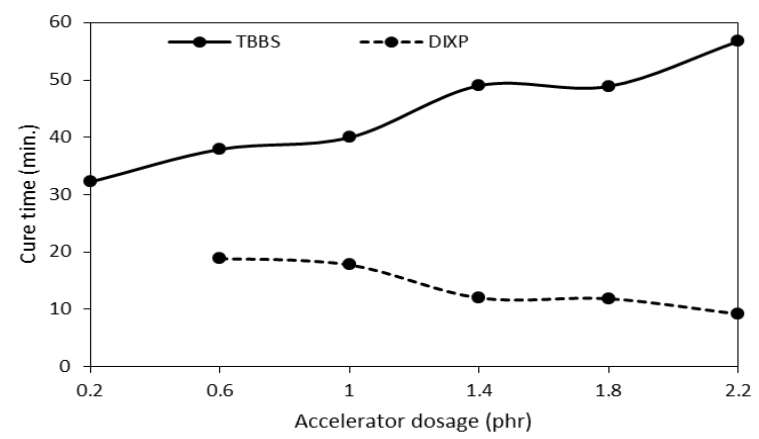

Fig. 6. Variation of cure time of DIXP and TBBS accelerated compounds

Maximum torque $\left(\mathrm{S}^{\prime} \max \right)$ generally corresponds with stiffness and shear modulus of vulcanized rubber and indicates the state of cross linking. As the concentration of both DIXP and TBBS increases, it is seen that $\mathrm{S}^{\prime} \max$ value also increases indicating an increase in the stiffness of the compounds (Fig. 7). Also the Fig. 7 shows that $\mathrm{S}^{\prime}$ max values observed for the compounds prepared with DIXP is low compared to that of the compounds prepared with TBBS. Hence, a lower state of cross linking and shear modulus is indicated for the former compounds in comparison to the latter compounds. Delta cure [(maximum-minimum) torque] of the former compounds is also lower than that of the latter compounds (Fig. 7) and this indicates a higher crosslink density for the compounds prepared with TBBS. This would result in higher stiffness or hardness for the vulcanizates prepared with TBBS (Coran, 1978). $\mathrm{S}^{\prime} \max$ and delta cure results of this study are not in agreement with the findings of Formela et al., (2015) who conducted a study on the effect of TBBS, CBS and TMTD accelerators on cure and mechanical properties of efficiently vulcanized (EV) unfilled thermo-mechanically reclaimed ground rubber tyre (GRT).

In the work conducted by Formela et al., $\mathrm{S}^{\prime} \max$ and delta cure values of vulcanizates prepared with TBBS and CBS were lower in compared to those of the vulcanizates prepared with the commonly used ultra-fast accelerator TMTD. This is probably due to the high sulphur donor activity of TMTD, which increases the crosslink density due to release of sulphur and hence the above mentioned two cure characteristics. From the results of the present study it appears that although DIXP is a sulphur donor accelerator ("Robac AS100 Robinson Brothers - datasheet," 2002), its activity is lower than that of TMTD. 


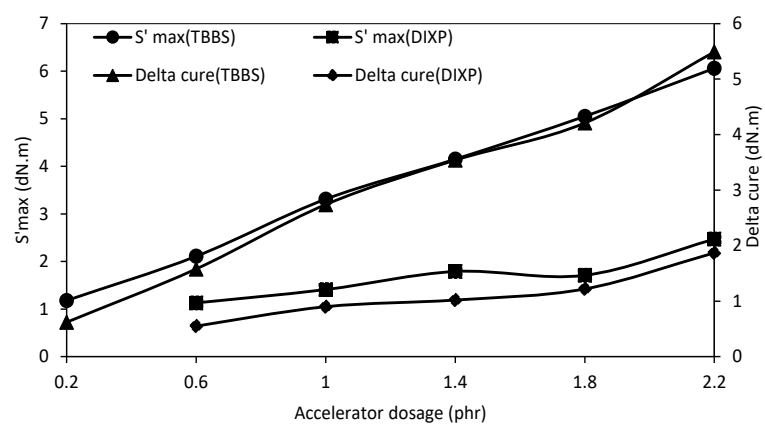

Fig. 7. Variation of $\mathrm{S}^{\prime}$ max and delta cure of DIXP and TBBS accelerated compounds

\section{Static mechanical properties}

The stress-strain curves of the NR vulcanizates prepared with DIXP and TBBS are shown in Fig. 8 and 9, respectively. The typical stress-strain curve of an elastomer is shown by the vulcanizate prepared with $2.2 \mathrm{phr}$ of DIXP and those of the other three vulcanizates prepared with lower dosages of the accelerator show a much lower value for stress at break (Fig. 8). On the other hand, vulcanizates prepared with TBBS show a progressive increase in stress at break with the increase in the dosage of the accelerator.

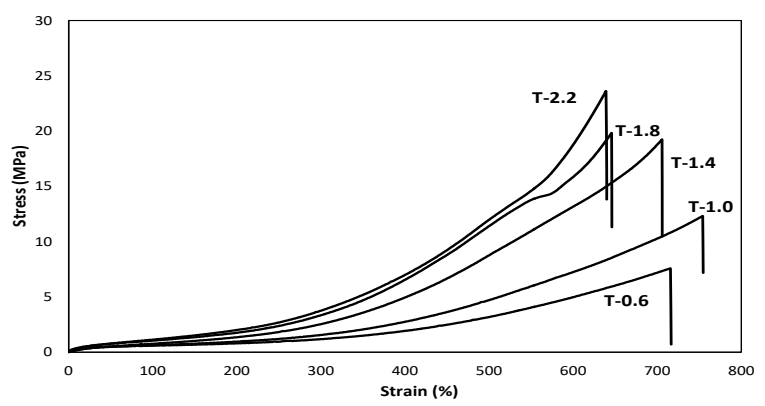

Fig. 8. Stress-strain curves of NR vulcanizates prepared with different DIXP dosages

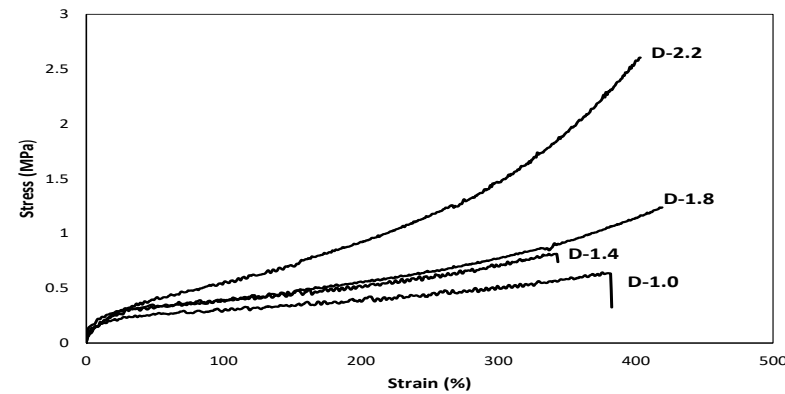

Fig. 9. Stress-strain curves of NR vulcanizates prepared with different TBBS dosages 
I H K Samarasinghe et al.

The vulcanizate prepared with DIXP shows lower values for tensile strength (Fig. 10) and elongation at break (Fig. 11) compared to those of the vulcanizate prepared with TBBS at the same dosage. This is in agreement with the work of Formela et al. (2015) conducted with TBBS, CBS and TMTD accelerators. In their study, vulcanizates prepared with TMTD showed higher tensile strength, elongation at break and modulus at $100 \%$ elongation due to higher crosslink density compared to those prepared with the two sulphenamide accelerators. In the present study also, the lower values for tensile strength of the vulcanizates containing DIXP could be attributed to lower crosslink density as indicated by the delta cure values (Fig. 7). As expected, the elongation at break values of the vulcanizates prepared with DIXP is lower than that of the vulcanizates prepared with TBBS at the same dosage (Fig. 11) and is in agreement with the results of tensile strength. The increasing trend of tensile strength of vulcanizates prepared with both DIXP and TBBS with the increase of the accelerator dosage could also be attributed to the increase in crosslink density as shown in Fig. 7 by the delta cure values. Elongation at break is expected to reduce with the increase of accelerator dosage due to the increase in crosslink density, which decrease mobility of elastomer chains. However, there is no decrease in elongation at break with the increase of accelerator dosage, especially in the case of the series of vulcanizates prepared with DIXP. Elongation at break of vulcanizates prepared with DIXP has increased with the increase of accelerator dosage.

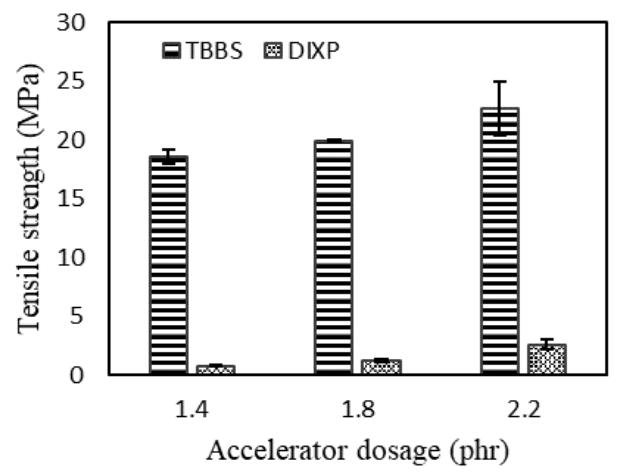

Fig. 10. Tensile strength of the vulcanizates prepared with DIXP and TBBS

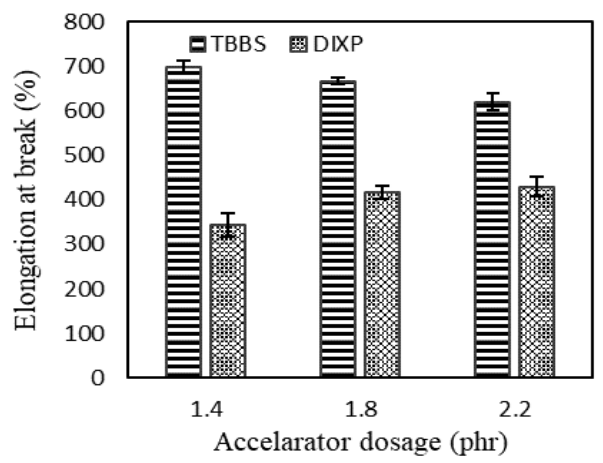

Fig. 11. Elongation at break of the vulcanizates prepared with DIXP and TBBS

Modulus at $100 \%$ and $300 \%$ elongations $\left(\mathrm{M}_{100}\right.$ and $\left.\mathrm{M}_{300}\right)$ increase in both the series of vulcanizates with increasing concentration of accelerators (Figs. 12 and 13) confirming the increase in crosslink density as indicated by the delta cure values (Fig. 7).

Fig. 14 shows the variation of hardness of the vulcanizates prepared with the two accelerators at different dosages. In general, hardness is a measure of 
Nitrosamine safe accelerators for dry rubber compounds

stiffness of a vulcanizate and it is of the vulcanizates is in agreement with directly proportional to modulus at that of $\mathrm{S}^{\prime} \max$ (Fig. 7) and modulus at $100 \%$ elongation. Variation of hardness $100 \%$ elongation (Fig. 12).

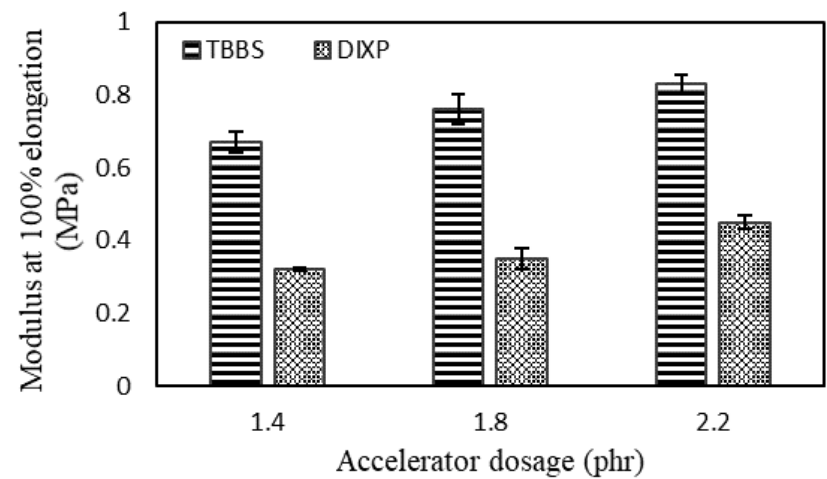

Fig. 12. $\mathrm{M}_{100}$ of the vulcanizates prepared with DIXP and TBBS

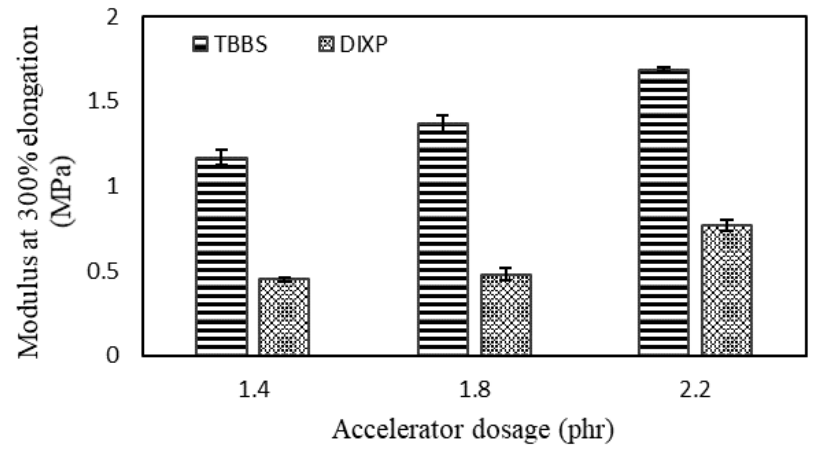

Fig. 13. $M_{300}$ of the vulcanizates prepared with DIXP and TBBS

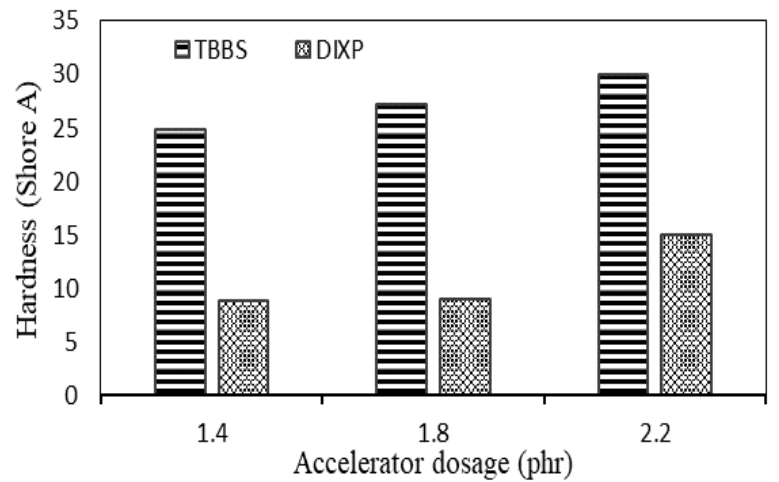

Fig. 14. Hardness of the vulcanizates prepared with DIXP and TBBS 
I H K Samarasinghe et al.

Tear strength indicates the capacity of the vulcanizates to resist cutting, chipping and tearing actions during service. As in the case of tensile strength, vulcanizates prepared with DIXP show a lower tear strength compared to the control vulcanizates prepared with TBBS indicating a lower resistance to crack propagation for the former vulcanizates (Fig. 15). Further, tear strength increases with increasing accelerator dosage for both the series of vulcanizates. The above behavior in tear strength may also be due to crosslink density variations as mentioned earlier for the other mechanical properties.

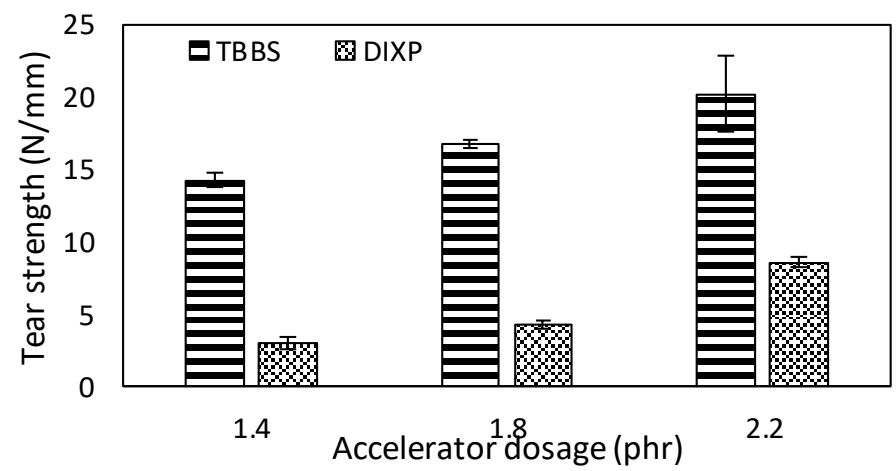

Fig. 15. Tear strength of the vulcanizates prepared with DIXP and TBBS

\section{Conclusion}

Although DIXP is known as a nitrosamine safe accelerator, most of the cure and static mechanical properties of NR compounds prepared with this accelerator are inferior to those of the compounds prepared with the commonly used nitrosamine safe accelerator TBBS. Nevertheless, NR compounds prepared with DIXP possess satisfactory results in regard to optimum cure time and elongation at break. In overall, results reveal that DIXP alone cannot be used in efficient vulcanization of NR compounds.

\section{Acknowledgements}

The authors are grateful to the staff of the Rubber Research Institute of Sri Lanka, Ratmalana and Department of
Chemical and Process Engineering, University of Moratuwa, Sri Lanka for their invaluable support given in regard to this study.

\section{References}

Anon. (2002). Robinson Brothers Limited. (2002). Robac AS100 Diisopropyl xanthogen polysulphide) A novel Accelerator for Rubber Vulcanization, (2002), electronic dataset, Robinson Brothers Limited, Phoenix Street, West Bromwich, B70 0AH UK, Fluker Post Research Project, viewed 12 June 2019, <https://polymer-additives.specialchem. com/product/a-robinson-brothers-robacas 100>.

Blackley, D C (2012). Polymer Lattices: Science and Technology Volume 3: Applications of Lattices. Springer Science \& Business Media. 
Coran, A Y (2003). Chemistry of the vulcanization and protection of elastomers: a review of the achievements. Journal of Applied Polymer Science 87(1), pp.24-30.

Coran, A Y (1978). Vulcanization in science and technology of rubber. Academic Press, San Diego, p.291.

Fishbein, L (2011). Potential Industrial Carcinogens and Mutagens 4, Elsevier.

Formela, K, Wąsowicz, D, Formela, M, Hejna, A and Haponiuk, J (2015). Curing characteristics, mechanical and thermal properties of reclaimed ground tire rubber cured with various vulcanizing systems. Iranian Polymer Journal 24(4), pp.289297.

Ghosh, P, Katare, S, Patkar, P, Caruthers, J $\mathrm{M}$, Venkatasubramanian, $\mathrm{V}$ and Walker, K A (2003). Sulfur vulcanization of natural rubber for benzothiazole accelerated formulations: from reaction mechanisms to a rational kinetic model. Rubber Chemistry and Technology 76(3), pp.592-693.

Goss, Jr, L C, Monthey, S and Issel, H M (2006). Review and the latest update of $\mathrm{N}$-nitrosamines in the rubber industry; The regulated, the potentially regulated, and compounding to eliminate nitrosamine formation. Rubber Chemistry and Technology 79(3), pp.541-552.

Iavicoli, I and Carelli, G (2006). Evaluation of occupational exposure to $\mathrm{N}$ - nitrosamines in a rubber-manufacturing industry. Journal of Occupational and Environmental Medicine 48(2), pp.195198.

Ohbi, D S, Purewal, T S, Shah, T and Siores, E (2007). Curing of bromobutyl elastomer composition using a xanthogen polysulphide accelerator for medical drug delivery device applications. Journal of Applied Polymer Science 106(1), pp.526533.

Proksch, E (2001). Review toxicological evaluation of nitrosamines in condoms. International Journal of Hygiene and Environmental Health 204 (2-3), pp.103110.

Stevenson, A, Robinson Brothers Ltd. (1987). Vulcanizable rubber compositions containing xanthogen polysulfide and xanthate compounds. U.S. Patent 4, 695, 609.

Vieira, E R, Pierozan, N J and Lovison, V (2006). Determination of N-nitrosamines and $\mathrm{N}$-nitrosables substances in rubber teats and soothers by GC-TEA. Brazilian Archives of Biology and Technology, 49(SPE), pp.73-78.

Address for correspondence: Mrs I H K Samarasinghe, Research Officer, Polymer Chemistry Dept., Rubber Research Institute of Sri Lanka, Telewala Road, Ratmalana, Sri Lanka.

e-mail:hasa86@gmail.com 